\title{
Investigational Medical Device
}

National Cancer Institute

\section{Source}

National Cancer Institute. Investigational Medical Device. NCI Thesaurus. Code C72968.

A device that is the subject of clinical investigation or research to determine the safety or effectiveness of the device. Investigational devices include transitional devices (21 CFR 812.3(r)) that are objects of investigations. An investigational device may be an approved device that is being studied for an unapproved use or efficacy. 